\title{
Homeostasis of Second Messenger Cyclic-di-AMP Is Critical for Cyanobacterial Fitness and Acclimation to Abiotic Stress
}

\section{OPEN ACCESS}

Edited by:

Conor P. O'Byrne,

National University of Ireland Galway,

Ireland

Reviewed by:

Iris Maldener,

Universität Tübingen, Germany

Juan Carlos Alonso,

Centro Nacional de Biotecnología

(CNB), Spain

Ronan Sulpice,

National University of Ireland Galway,

Ireland

*Correspondence:

Beronda L. Montgomery

montg133@msu.edu

${ }^{\dagger}$ Present address:

Marco Agostoni,

California Institute for Quantitative Biosciences, University of California, Berkeley, Berkeley, CA, United States

Eric L. Bruger,

Department of Biological Sciences,

University of Idaho, Moscow, ID, United States

Specialty section:

This article was submitted to Microbial Physiology and Metabolism, a section of the journal Frontiers in Microbiology

Received: 22 January 2018 Accepted: 11 May 2018 Published: 29 May 2018

Citation: Agostoni M, Logan-Jackson AR, Heinz ER, Severin GB, Bruger EL, Waters CM and Montgomery BL

(2018) Homeostasis of Second Messenger Cyclic-di-AMP Is Critical for Cyanobacterial Fitness and Acclimation to Abiotic Stress.

Front. Microbiol. 9:1121.

doi: 10.3389/fmicb.2018.01121

\section{Marco Agostoni1,2†, Alshaé R. Logan-Jackson ${ }^{2,3}$, Emily R. Heinz², Geoffrey B. Severin ${ }^{4}$, Eric L. Bruger ${ }^{37}$, Christopher M. Waters ${ }^{1,3}$ and Beronda L. Montgomery ${ }^{1,2,3,4 *}$}

${ }^{1}$ Cell and Molecular Biology Graduate Program, Michigan State University, East Lansing, MI, United States, ${ }^{2}$ Department of Energy Plant Research Laboratory, Michigan State University, East Lansing, MI, United States, ${ }^{3}$ Department of Microbiology and Molecular Genetics, Michigan State University, East Lansing, MI, United States, ${ }^{4}$ Department of Biochemistry and Molecular Biology, Michigan State University, East Lansing, MI, United States

Second messengers are intracellular molecules regulated by external stimuli known as first messengers that are used for rapid organismal responses to dynamic environmental changes. Cyclic di-AMP (c-di-AMP) is a relatively newly discovered second messenger implicated in cell wall homeostasis in many pathogenic bacteria. C-di-AMP is synthesized from ATP by diadenylyl cyclases (DAC) and degraded by specific c-di-AMP phosphodiesterases (PDE). C-di-AMP DACs and PDEs are present in all sequenced cyanobacteria, suggesting roles for c-di-AMP in the physiology and/or development of these organisms. Despite conservation of these genes across numerous cyanobacteria, the functional roles of c-di-AMP in cyanobacteria have not been well-investigated. In a unique feature of cyanobacteria, phylogenetic analysis indicated that the broadly conserved DAC, related to CdaA/DacA, is always co-associated in an operon with genes critical for controlling cell wall synthesis. To investigate phenotypes regulated by c-di-AMP in cyanobacteria, we overexpressed native DAC (s/l0505) and c-di-AMP PDE (s/r0104) genes in the cyanobacterium Synechocystis sp. PCC 6803 (hereafter Synechocystis) to increase and decrease intracellular c-di-AMP levels, respectively. DAC- and PDE-overexpression strains, showed abnormal aggregation phenotypes, suggesting functional roles for regulating c-di-AMP homeostasis in vivo. As c-di-AMP may be implicated in osmotic responses in cyanobacteria, we tested whether sorbitol and $\mathrm{NaCl}$ stresses impacted expression of s//0505 and s/r0104 or intracellular c-di-AMP levels in Synechocystis. Additionally, to determine the range of cyanobacteria in which c-di-AMP may function, we assessed c-di-AMP levels in two unicellular cyanobacteria, i.e., Synechocystis and Synechococcus elongatus PCC 7942, and two filamentous cyanobacteria, i.e., Fremyella diplosiphon and Anabaena sp. PCC 7120. C-di-AMP levels responded differently to abiotic stress signals in distinct cyanobacteria strains, whereas salt stress uniformly impacted another second messenger cyclic di-GMP in cyanobacteria. Together, these results suggest regulation of c-di-AMP homeostasis in cyanobacteria and implicate a role for the second messenger in maintaining cellular fitness in response to abiotic stress.

Keywords: abiotic stresses, c-di-AMP, c-di-GMP, cyanobacteria, ionic stress, osmotic stress, salt stress, second messengers 


\section{INTRODUCTION}

Cyanobacteria comprise a group of highly diverse, oxygenic photosynthetic bacteria that respond to a range of abiotic and biotic signals in their environment, from light that has direct impacts on photosynthesis and productivity to osmotic and saline stresses. These organisms are highly abundant in many ecosystems (Garcia-Pichel et al., 2003) and as carbon, and sometimes nitrogen fixers, contribute significantly to global carbon and nitrogen cycles. Second messengers are critical intracellular molecules that are regulated in response to specific external stimuli known as first messengers. Control of second messenger homeostasis is used frequently to initiate physiological changes that occur in microorganisms as a part of environmental acclimation. A range of second messengers have been identified that play key roles in regulating environmentally-controlled physiological responses in cyanobacteria (Agostoni and Montgomery, 2014). Among second messengers, cyanobacteria commonly rely on cyclic nucleotide signaling molecules such as cyclic AMP (i.e., cAMP) (Ohmori et al., 1988, 2001, 2002; Katayama and Ohmori, 1997; Terauchi and Ohmori, 1999, 2004; Ohmori and Okamoto, 2004; Okamoto et al., 2004; Imashimizu et al., 2005) and cyclic GMP (i.e., cGMP) (Ochoa De Alda et al., 2000; Cadoret et al., 2005). However, dicyclic nucleotides such as cyclic dimeric GMP (hereafter, cyclic di-GMP or c-di-GMP) have only recently been reported in these organisms. In cyanobacteria, c-di-GMP has roles in acclimation to light, phototaxis, and cellular aggregation (Savakis et al., 2012; Agostoni et al., 2013, 2016; Enomoto et al., 2014, 2015; Angerer et al., 2017).

The second messenger cyclic dimeric AMP (hereafter, cyclic di-AMP or c-di-AMP) is a relatively newly discovered cyclic dinucleotide (Romling, 2008; Witte et al., 2008; Fu et al., 2016; Jenal et al., 2017; Krasteva and Sondermann, 2017). Cyclic di-AMP is synthesized by diadenylyl cyclase (DAC; PF02457) from two molecules of ATP and degraded by specific phosphodiesterase (PDE) enzymes into pApA (Corrigan and Grundling, 2013). Cyclic di-AMP and its functional roles in vivo have been studied primarily in Gram-positive bacteria. In Grampositive species, the regulation of c-di-AMP homeostasis has been associated with a range of responses. Cyclic di-AMP levels impact growth (Witte et al., 2013; Rismondo et al., 2016; Whiteley et al., 2017), sporulation (Oppenheimer-Shaanan et al., 2011; Mehne et al., 2014; Zheng et al., 2015; Raguse et al., 2017), virulence (Bai et al., 2013; Cho and Kang, 2013; Du et al., 2014; Yang et al., 2014; Dey et al., 2015), biofilm formation related to hostmicrobe interactions (Townsley et al., 2018), and DNA repair damage responses or the coordination of DNA damage response and stress homeostasis (Bejerano-Sagie et al., 2006; Witte et al., 2008; Gándara and Alonso, 2015; Gándara et al., 2017; Raguse et al., 2017), among other phenotypes in a range of Gram-positive strains. A role for c-di-AMP in growth and virulence has also been observed for the Gram-negative Borrelia burgdorferi and Chlamydia trachomatis (Barker et al., 2013; Ye et al., 2014). Additionally, c-di-AMP has been implicated in cellular responses to abiotic stresses in multiple Gram-positive bacteria (Dengler et al., 2013; Bowman et al., 2016; Zhu et al., 2016).
Whereas numerous roles for c-di-AMP have been documented in Gram positive bacteria, limited insights into the roles of this molecule in other bacteria have been reported. Notably, cyanobacteria have recently been reported to contain c-di-AMP synthesis genes (Agostoni and Montgomery, 2014) and c-di-AMP accumulation has recently been reported in Synechococcus elongatus sp. PCC 7942 (Rubin et al., 2018). All sequenced cyanobacteria possess at least one DAC, with some exceptions of strains that carry two DACs (Agostoni and Montgomery, 2014). Unlike those DAC proteins reported in many bacteria which include a DAC domain with fusions to other regulatory domains, the DACs of cyanobacteria generally contain only the cyclase enzymatic domain. Additionally, two specific c-di-AMP PDEs have been discovered in bacteria: one containing a DHH-DHHA1 domain (Romling, 2008; Corrigan and Grundling, 2013), a class which is likely not present in cyanobacteria; the other with a domain architecture similar to the 7TM_7TMR_HD protein family (Huynh et al., 2015). The 7TM_7TMR_HD is more common than DHH-DHHA1 domain-containing PDEs in bacteria and it is also present in cyanobacterial genomes (Huynh et al., 2015; Huynh and Woodward, 2016).

Recently, an assessment of regulons of riboswitches involved in binding the second messenger c-di-AMP suggested a function of c-di-AMP in regulating the synthesis of osmoprotectants under abiotic stress in cyanobacteria (Nelson et al., 2013). The addition of organic solutes, which are not permeable to the bacterial cell, to cellular growth medium induces osmotic stress. Although salt stress is often referred to as osmotic stress (Hagemann, 2011), salt stress specifically results in reduced water availability due to dissolved ions that concomitantly induce osmotic stress (Pade and Hagemann, 2015). Thus, salt stress includes both ionic stress and secondary osmotic stress. The primary signals induced in response to salt and osmotic stress in cyanobacteria are still being elucidated (Pade and Hagemann, 2015). However, a role for two component histidine kinase Hik33 in responses to osmotic and salt stress in cyanobacteria has been noted (Mikami et al., 2002; Marin et al., 2003; Paithoonrangsarid et al., 2004; Shoumskaya et al., 2005). The primary abiotic stress can also induce secondary signals, including second messengers. In cyanobacteria, the second messenger $\mathrm{Ca}^{2+}$ is involved in organismal responses to environmental osmotic and salt changes (Torrecilla et al., 2001). The recognition that potential c-di-AMP binding riboswitches may be involved in osmoprotectant production in response to osmotic stress in cyanobacteria suggests a potential role for c-di-AMP in cellular responses to abiotic stress.

In this study, we investigated the activity of DAC and PDE enzymes in the moderately halotolerant freshwater unicellular cyanobacterium Synechocystis, the potential for abiotic stresses to alter intracellular c-di-AMP levels, and the impact of altering c-di-AMP homeostasis on the physiology and survival of this organism. Furthermore, we assessed the impacts of osmotic and salt stresses on modulating c-di-AMP homeostasis in several additional 
cyanobacteria, including another freshwater unicellular strain Synechococcus elongatus PCC 7942 (hereafter Synechococcus) for which c-di-AMP has been recently implicated in nighttime survival (Rubin et al., 2018), and two filamentous freshwater strains Fremyella diplosiphon [also known as Tolypothrix sp. PCC 7601 (Yerrapragada et al., 2015)], and Anabaena sp. PCC 7120 (hereafter Anabaena, also known as Nostoc sp. PCC 7120) to more broadly understand the modulation of c-di-AMP homeostasis across a range of cyanobacteria.

\section{MATERIALS AND METHODS}

\section{Plasmid Construction in Synechocystis}

Intracellular levels of c-di-AMP in Synechocystis were targeted for increase by overexpressing the native DAC protein Sll0505 or reduction by overexpressing the native PDE protein Slr0104. The open reading frame of native genes encoding the DAC and PDE enzymes were constitutively overexpressed under the control of the apcE (slr0335) promoter using the selfreplicating plasmid pRL1342 (Wolk et al., 2007; GenBank: AF403427.1). Promoters were added to the DAC- or PDEencoding genes by overlap PCR using primers indicated in Table 1. The genes were amplified from genomic DNA with PrimeSTAR Max DNA polymerase (Clontech Laboratory, Inc.) using primers that encoded XhoI and BamHI restriction sites (Table 1). The promoter-gene fusion product and pRL1342 were restricted with $\mathrm{XhoI}$ and $\mathrm{BamHI}$ and the cleaved products ligated using DNA Ligation Kit, Mighty Mix (Takara). After transformation of the ligation mix into E. coli $\mathrm{DH} 5 \alpha$ competent cells (Life Technologies, Inc.), transformants were selected on $\mathrm{LB}$ agar containing chloramphenicol at $50 \mu \mathrm{g} \mathrm{mL}^{-1}(\mathrm{w} / \mathrm{v})$. The DNA sequences of isolated plasmids were confirmed by Sanger sequencing. The plasmid was then inserted into Synechocystis by triparental mating as previously described (Agostoni et al., 2016).

\section{Culture Conditions}

Axenic cultures of Synechocystis, F. diplosiphon, Synechococcus, and Anabaena were grown at $28^{\circ} \mathrm{C}$ in BG-11 (Allen, 1968) containing $20 \mathrm{mM}$ HEPES at pH 8.0 (hereafter BG-11/HEPES) with the indicated antibiotic when needed. F. diplosiphon strain SF33, a shortened-filament mutant strain that displays wildtype (WT) pigmentation (Cobley et al., 1993), was used as the WT F. diplosiphon strain. Cultures $(25 \mathrm{ml})$ in $250 \mathrm{ml}$ glass flasks were adapted to fluorescent white light (WL; Philips F32T8/TL741/ALTO) at $15 \mu \mathrm{mol} \mathrm{m}{ }^{-2} \mathrm{~s}^{-1}$ with shaking at $175 \mathrm{rpm}$ for at least a week. Growth rate of the WT, overexpression (OE) DAC, and OE PDE strains was estimated by optical density at $750 \mathrm{~nm}\left(\mathrm{OD}_{750}\right)$ every day for strains grown under WL (Philips F32T8/TL741/ALTO) at $35 \mu \mathrm{mol} \mathrm{m} \mathrm{m}^{-2} \mathrm{~s}^{-1}$ with shaking at $175 \mathrm{rpm}$. A secondary analysis of growth was conducted on BG-11 plates containing $1 \%(\mathrm{w} / \mathrm{v})$ agar. A 1:10 dilution series of cells growing homogenously in liquid culture was plated for each strain with the initial cultures at an $\mathrm{OD}_{750}$ of
0.6. Aliquots of $10 \mu \mathrm{L}$ of the dilutions up to $1: 10,000$ were plated and the plates incubated under $15 \mu \mathrm{mol} \mathrm{m}^{-2} \mathrm{~s}^{-1}$ of WL.

\section{Abiotic Stresses and c-di-AMP/c-di-GMP Quantification}

Cells were grown to an optical density at $750 \mathrm{~nm}\left(\mathrm{OD}_{750}\right)$ of 1 and transferred to new $250 \mathrm{ml}$ flasks with BG-11/HEPES medium containing $0.2 \mathrm{M}$ sorbitol for the osmotic stress, or $0.2 \mathrm{M} \mathrm{NaCl}$ for the ionic stress, except for halophile Synechocystis for which the $\mathrm{NaCl}$ concentration was $0.6 \mathrm{M}$. As a control, BG-11/HEPES medium without sorbitol or $\mathrm{NaCl}$ added was utilized. Cells were maintained under osmotic or salt stress for $24 \mathrm{~h}$. After $24 \mathrm{~h}, \mathrm{c}$-di-AMP and c-di-GMP were quantified as described (Massie et al., 2012; Agostoni et al., 2013; Barker et al., 2013). In brief, c-di-AMP and c-di-GMP were quantified by UPLC-MS/MS. Prior to analysis, an aliquot of each sample was dried under vacuum to remove extraction buffer and the pellet was resuspended in an equal volume of water. A 10$\mu l$ volume of the resuspended sample was analyzed together with an eight-point standard curve of purified c-di-AMP or c-di-GMP (Biolog). C-di-AMP and c-di-GMP concentrations determined for samples were normalized to total soluble protein content from an equal volume of cells from which second messengers were extracted as previously described (Agostoni et al., 2013; Zhu et al., 2016). Growth over time of WT, OE DAC and OE PDE Synechocystis stains in the presence of sorbitol $(0.5 \mathrm{M})$ or $\mathrm{NaCl}(0.6 \mathrm{M})$ was measured using $\mathrm{OD}_{750}$ as described above.

\section{Quantitative Reverse Transcriptase PCR (qRT-PCR) and RT-PCR in Synechocystis}

For RNA extraction, Synechocystis cells from a $10 \mathrm{ml}$ aliquot of culture were collected $24 \mathrm{~h}$ after the osmotic stress or after subculturing. RNA was isolated using Trizol reagent essentially as described (Seib and Kehoe, 2002; Singh and Montgomery, 2013a). Total RNA extracted was treated with a TURBO DNAfree kit (Ambion, Austin, TX, United States). cDNA synthesis was performed as described (Pattanaik and Montgomery, 2010) with $0.5 \mu \mathrm{g}$ of total RNA using the Reverse Transcription System (Promega Corporation, Madison, WI, United States). Control reactions were conducted in which no reverse transcriptase (No $\mathrm{RT}$ ) was added to the reaction mixtures. Gene $\operatorname{rnpB}$ (RNase P subunit B), the expression of which is not altered by nutrient or salt stress (Kloft et al., 2005; Zhang et al., 2007; Wang et al., 2014), was used as an internal control. RT cycling parameters were denaturing at $95^{\circ} \mathrm{C}$ for $20 \mathrm{~s}, 40$ cycles of denaturation at $95^{\circ} \mathrm{C}$ for $3 \mathrm{~s}$ and annealing/extension at $60^{\circ} \mathrm{C}$ for $30 \mathrm{~s}$, followed by melt-curve analysis starting at $60^{\circ} \mathrm{C}$ and ending at $95^{\circ} \mathrm{C}$ for 15 min. Table 1 shows primers used for qRT-PCR and RTPCR.

\section{Genome Comparisons}

Phylogenetic analyses of multiple conserved DAC domain sequences (PF02457) from 83 finished cyanobacterial genomes present in the IMG database were performed using SeaView4 software (Galtier et al., 1996). Multiple alignments of amino 
TABLE 1 | Primers used in this study.

\begin{tabular}{|c|c|c|c|}
\hline & Forward primer $\left(5^{\prime}-3^{\prime}\right)^{a}$ & Reverse primer $\left(5^{\prime}-3^{\prime}\right)$ & Purpose \\
\hline OEsll0505_npapcE & CGCGCTCGAGTTAAAACTGCATTATCAG & CTGTCAATGGCGACTCCCCGATTGAGGAAA & DAC cloning \\
\hline OEs/l0505 & TICCTCAATCGGGGAGTCGCCATTGACAG & CGCGGATCCTCATIITTGTCGTT & DAC cloning \\
\hline OEslr0104_npapcE & CGCGCTCGAGTTAAAACTGCATTATCAG & GGCAAAAATTGCTTCATTGGATITCATTATCTCCC & PDE cloning \\
\hline OEslr0104 & GGGAGATAATGAAATCCAATGAAAGCAATIIITGCC & CTCGGATCCCTAAAATCTGGTGGTG & PDE cloning \\
\hline sll0504 & ACCGGATGAACGACGAAATTA & TAGACAATCCTGGCGCAATAG & RT-PCR/qRT-PCR \\
\hline s/l0505 & GGAGTCGCCATTGACAGTAA & TCCTCGGAAACGACAATACAA & RT-PCR/qRT-PCR \\
\hline sll0506 & CCGGATTTGGACCAGCA & TCCTTAATTCCCGCCGTAG & RT-PCR/qRT-PCR \\
\hline slr0104 & CGCCCAACTCAAACAAGAAAG & GTTGCTGCTCCAGGGTAAA & RT-PCR/qRT-PCR \\
\hline rnpB & GTGAGGACAGTGCCACAGAA & GGCAGGAAAAAGACCAACCT & qRT-PCR \\
\hline
\end{tabular}

${ }^{a}$ Bold text indicates sequence of restriction site.

acid sequences were generated using MUSCLE (Edgar, 2004). Phylogenetic trees were inferred using maximum likelihoodbased method 100 bootstraps, and the Jones-Taylor-Thornton model (Jones et al., 1992). The likelihood log was -23144.7 .

\section{Cell Lysis Assay}

The cell lysis assay was conducted by pelleting $7 \mathrm{~mL}$ of cells that had been grown in BG-11/HEPES medium under WL at $15 \mu \mathrm{mol} \mathrm{m} \mathrm{m}^{-2} \mathrm{~s}^{-1}$ as described above and diluted to an $\mathrm{OD}_{750}$ of 0.4 and incubated for an additional $24 \mathrm{~h}$. Pelleted cells were then resuspended in $4 \mathrm{~mL}$ of CelLytic ${ }^{\mathrm{TM}} \mathrm{B}$ (Millipore Sigma, St. Louis, MO, United States) containing $10 \mu \mathrm{g} / \mathrm{mL}$ (w/v) lysozyme and shaken on a vortexer for $30 \mathrm{~min}$. After this period, samples were centrifuged at $10,000 \times g$ at room temperature for $5 \mathrm{~min}$. The level of cellular lysis was estimated based on measuring absorbance at $660 \mathrm{~nm}$ of the chlorophyll released into the supernatant (Mehta et al., 2015). Chlorophyll absorbance values were standardized relative to total soluble protein content of cells.

\section{Statistical Analysis}

Experiments were conducted with at least three independent biological replicates. Statistical significance was determined via Student's $t$-test or via one way analysis of variance (ANOVA) with Fisher post hoc test using OpenStat statistical software (version 10.01.08; W. G. Miller http://www.Statprograms4U.com). Statistical analyses were performed utilizing 95\% confidence intervals $(p<0.05)$.

\section{RESULTS}

\section{Bioinformatic and Evolutionary Analyses of c-di-AMP Synthesis Genes in Cyanobacteria}

Nearly all sequenced cyanobacteria assessed contain one copy of the c-di-AMP synthesis gene DAC, with the exception of Cyanothece sp. PCC 7424, Cyanothece sp. PCC 7822, Gloeobacter kilaueensis JS1, and Gloeobacter violaceus PCC 7421, which each carry two copies (Agostoni and Montgomery, 2014). Notably, DACs from cyanobacteria lack additional sensor domains (Agostoni and Montgomery, 2014), in contrast to DACs from other bacteria that contain domains involved in multimerization or in regulating enzymatic activity (Corrigan and Grundling, 2013; Commichau et al., 2015). The genus Gloeobacter, which represents primordial cyanobacteria (Turner et al., 1999), possesses both DACs suggesting that c-di-AMP signaling was present early during the evolution of this phylum. Phylogenetic analysis based on amino acid sequences of DACs in cyanobacteria (Figure 1) indicated that DACs have been vertically transferred as the typology of the tree is similar to one generated based on phylogenetic diversity of cyanobacterial genomes (Shih et al., 2013). For cyanobacterial species with two DACs, one of the two copies is extremely divergent from that of all the other DACs found in species with just one copy (Figure 1, indicated as " $2^{\text {nd }} \mathrm{DAC}$ "). The diverged copy of DAC is related to other unknown or hypothetical DAC enzyme-encoding genes that contain a DisA-N domain, which may indicate a novel class of DAC enzymes.

Cyanobacteria exhibit a conserved operon structure for the DAC gene related to $c d a A / d a c A$ that is found broadly across distinct strains. The Diaminopimelate Decarboxylase (DAPDC or $l y s A$ ) and Undecaprenyl Pyrophosphate Synthase (UPS or $u p p S$ ) genes are always downstream and upstream, respectively, from the DAC gene which is conserved across cyanobacteria (Figure 2A). It appears that the grouping of these three genes in an operon is a unique feature of cyanobacteria, as this arrangement is absent in non-cyanobacterial species. In species with two DACs, only one DAC is found in this gene arrangement (data not shown). DAPDC catalyzes the last step in the biosynthesis of the amino acid lysine, i.e., conversion of the peptidoglycan precursor DAP to lysine (Bukhari and Taylor, 1971a,b). UPS is a prenyltransferase that catalyzes the production of undecaprenyl pyrophosphate, which is critical as a lipid carrier for peptidoglycan synthesis (Apfel et al., 1999). Thus, both neighboring genes appear to be implicated in peptidoglycan synthesis. In Synechocystis, there is a $42 \mathrm{bp}$ intergenic region between the DAPDC gene (sll0504) and DAC gene (sll0505), whereas the DAC overlaps with the UPS gene (sll0506). We decided to verify whether the three genes were cotranscribed. RT-PCR analyses of amplicons of portions of the mRNA indicated that the three genes can be transcribed together in a single operon in Synechocystis (Figure 2B, lane 6), suggesting that they may be involved in similar or related functions in the organism. 


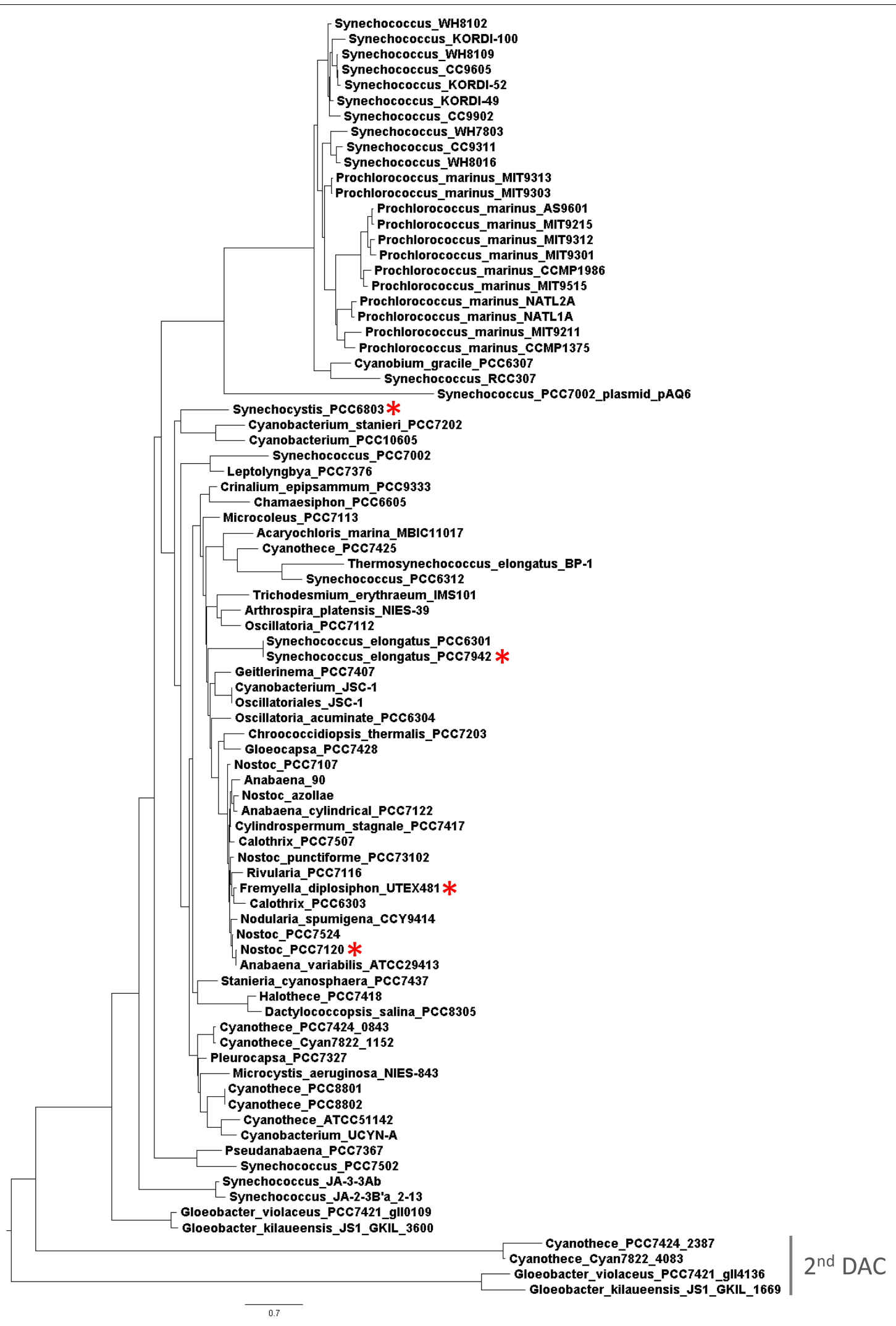

FIGURE 1 | Phylogenetic analysis based on multiple putative functionally conserved DAC sequences. For the species with two DACs (see gray line for the second rare $\mathrm{DAC}$ ), the gene identification number was added. Red asterisks indicate four species investigated in this study. 


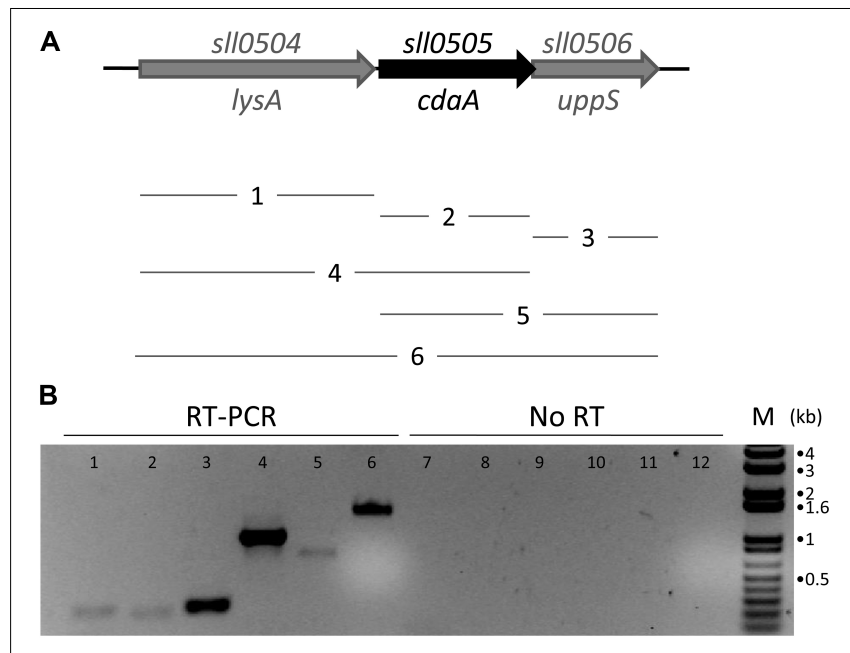

FIGURE 2 | Genomic context and RT-PCR analyses of conserved DAC-containing operon in Synechocystis. (A) Genomic context of conserved DAC (s/l0505) in Synechocystis. Lines (1-6) below genomic region indicate PCR products amplified from cDNA in panel B. RT-PCR of DAPDC (s//0504), DAC (s/l0505), and UPS (s/l0506) in Synechocystis. (B) RT-PCR analyses of transcripts produced from the DAC genomic region in Synechocystis: Lanes 1 and 7, DAPDC; Lanes 2 and 8, DAC; Lanes 3 and 9, UPS; Lanes 4 and 10, DAPDC and DAC; Lanes 5 and 11, DAC and UPS; Lanes 6 and 12, DAPDC DAC, and UPS. Lanes 1-6, RT-PCR reactions; Lanes 7-12, no RT negative control reactions. $\mathrm{M}$, molecular marker. RNA was isolated from cells grown at $35 \mu \mathrm{mol} \mathrm{m} \mathrm{m}^{-2} \mathrm{~s}^{-1}$ white light.

\section{Overexpression of Native DAC-Encoding sll0505 and PDE-Encoding s/r0104 Genes in Synechocystis}

In Synechocystis there is only one DAC (PF02457, sll0505), which is related to $c d a A / d a c A$, and one c-di-AMP PDE (PF07698, slr0104, belonging to the 7TM_7TMR_HD family), which is related to $p g p H$. In many bacteria c-di-AMP is essential for survival (Commichau et al., 2015), and in accordance with this observation, we were not able to produce a mutant completely lacking sll0505 in Synechocystis (data not shown). We, thus, decided to overexpress the c-di-AMP DAC and PDE native enzymes in Synechocystis to investigate their activity in vivo. Quantitative RT-PCR showed increased accumulation of the mRNA for DAC and PDE genes in the DAC and PDE overexpression strains, respectively (Figure 3 ). The DAC strain exhibited an $\sim 40$-fold increase in the level of DAC mRNA accumulation compared to WT (Figure 3A), whereas the PDE strain had a more than 200-fold increase in PDE mRNA levels compared to WT (Figure 3B).

Quantification of c-di-AMP levels in the DAC and PDE overexpression strains was conducted to assess whether these two native enzymes could modulate intracellular levels of c-di-AMP (Figure 4). The levels of c-di-AMP in the DAC overexpression strain were significantly altered, i.e., 1.7-fold higher $(p<0.05)$, compared to the WT strain. Whereas this is lower than might be anticipated based on gene expression data, some bacterial strains which overaccumulate DAC mRNA show no upregulation of intracellular c-di-AMP levels suggesting possible negative feedback mechanisms on DAC activity in some cases (Savage et al., 2015). The levels of c-di-AMP in the PDE overexpression Synechocystis strain were on average half as much as the WT strain, although this level was not significantly different. To assess whether the overexpression of the DAC and c-di-AMPspecific PDE were specific to affecting c-di-AMP levels, we assessed levels of another second messenger c-di-GMP. We observed no difference in c-di-GMP levels between WT, DACoverexpression strain, and c-di-AMP PDE overexpression strain (data not shown).

Previously, it has been observed that c-di-AMP homeostasis is fundamental for optimal growth, with either lower than normal levels or overaccumulation relative to WT resulting in defects in growth (Corrigan et al., 2013; Mehne et al., 2013; Ye et al., 2014; Gundlach et al., 2015; Rubin et al., 2018). Our overexpressing strains both exhibited a lag in growth compared to WT in BG-11/HEPES medium (Figure 5A). Additionally, WT grew homogenously in the medium, whereas DAC and PDE strains formed distinct aggregates in the late part of the growth curve analysis (Figure 5B). This aggregation may impact analysis of growth by measuring culture optical density. Thus, we also assessed growth using dilution-based colony growth assays on agar plates. In this assay, we similarly observed that the OE DAC and OE PDE strains exhibited impaired growth relative to WT (Figure 5C).

Given the association of the c-di-AMP synthesis gene with other genes associated with peptidoglycan synthesis or modification and the cellular aggregation phenotypes, c-diAMP accumulation in cells may impact cell wall synthesis or modification. We, thus, tested for alterations in cell wall properties for the $\mathrm{OE}$ strains relative to WT by conducting lysozyme sensitivity assays. Both the OE DAC strain and OE PDE strain had increased sensitivity to lysozyme treatment relative to WT, as measured by chlorophyll release into the supernatant (Figure 6).

\section{Osmotic and Salt Stresses Impact c-di-AMP Levels in Multiple Cyanobacteria}

Based on the observation that c-di-AMP-binding riboswitches have a putative role in osmoprotectant synthesis and transport in cyanobacteria (Nelson et al., 2013), c-di-AMP could be critical for osmotic or salt stress responses in these organisms. Osmoprotectants have recognized roles in cellular responses to both osmotic and salt stresses (Bougouffa et al., 2014). Thus, we quantified changes in DAC and PDE mRNA levels in WT under osmotic and salt stresses, the latter of which induces both osmotic and ionic stress. After $24 \mathrm{~h}$ of osmotic or salt stress, levels of DAC and PDE mRNA decreased compared to non-stress, control conditions although differences were not statistically significant (Figure 3). The DAC mRNA levels decreased to 0.3 - and 0.7 -fold relative to WT under sorbitol and salt stress, respectively (Figure 3A). Similarly, the PDE mRNA levels decreased to 0.5- and 0.7fold relative to WT under sorbitol and salt stress, respectively (Figure 3B). 


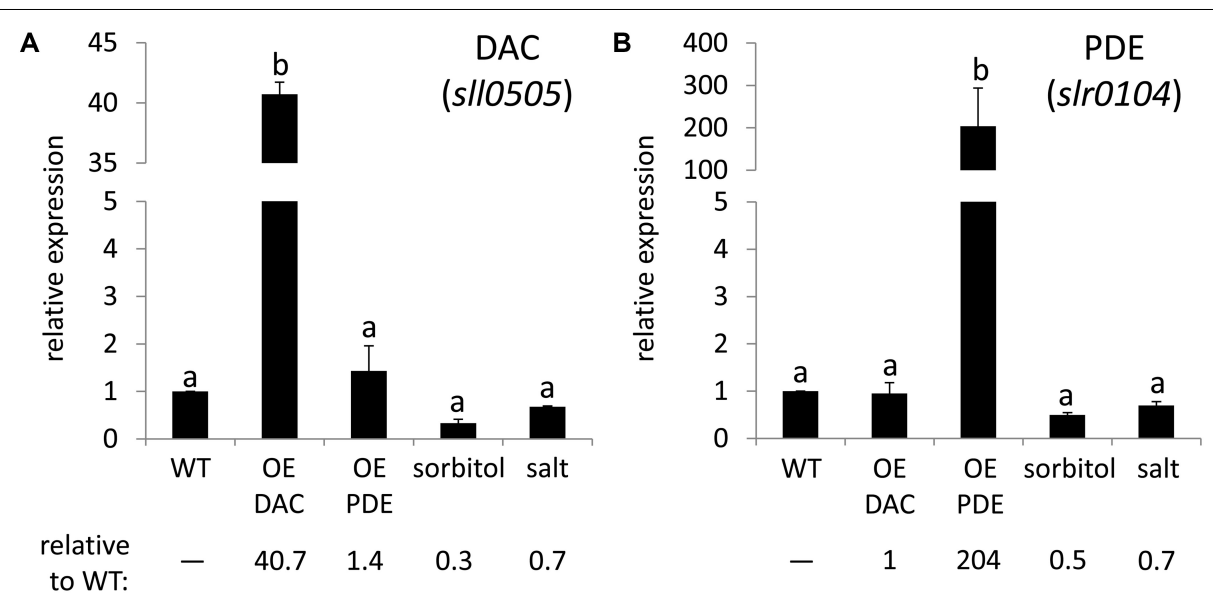

FIGURE 3 | Quantitative reverse transcriptase PCR (qRT-PCR) analysis of the expression of DAC and PDE genes in Synechocystis. (A) DAC and (B) PDE genes were analyzed for strains grown under $35 \mu \mathrm{mol} \mathrm{m} \mathrm{m}^{-2} \mathrm{~s}^{-1}$ white light. Wild-type (WT), overexpression of DAC (s/l0505) in WT (OE DAC), overexpression of PDE (slr0104) in WT (OE PDE), WT under sorbitol stress (sorbitol, $0.2 \mathrm{M}$ sorbitol), WT under salt stress (salt, $0.6 \mathrm{M}$ NaCl). The transcript level of the rnpB gene was used as an internal control for each sample. Bars represent averages ( \pm standard deviations). Bars marked with different letters are significantly different $(p<0.05)$. Numbers below graphs represent fold difference relative to WT grown under non-stress conditions.

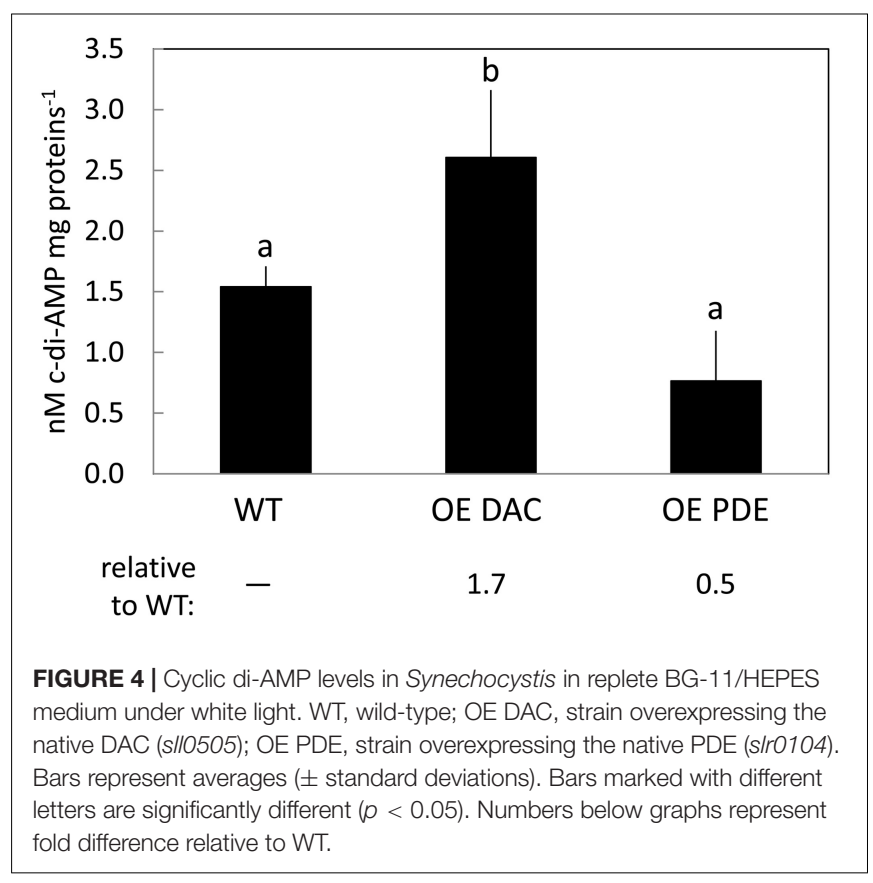

To determine whether these stresses influence intracellular c-di-AMP levels and whether stress-induced changes occur in cyanobacteria beyond Synechocystis, we exposed Synechocystis and three additional species of cyanobacteria to sorbitol or salt stress for $24 \mathrm{~h}$. Two were unicellular cyanobacteria, moderately halotolerant Synechocystis (Reed et al., 1985) and salt-sensitive Synechococcus (Kaku et al., 2000), and two were filamentous cyanobacteria, highly salt-sensitive Anabaena (Rai and Tiwari, 2001) and salt-sensitive F. diplosiphon (Singh and Montgomery, 2013b). C-di-AMP levels were threefold higher under sorbitolinduced osmotic stress in Synechocystis. By comparison, there was no significant difference in intracellular levels of c-diAMP in another unicellular strain Synechococcus in response to osmotic stress (Figure 7A). In the filamentous cyanobacterium F. diplosiphon, c-di-AMP levels were much higher than for the other cyanobacterial strains and increased $\sim 2$-fold under osmotic stress, whereas sorbitol treatment did not result in an increase in c-di-AMP under our conditions in Anabaena (Figure 7A). Changes in the intracellular concentration of c-di-AMP occur during osmotic stress in Synechocystis and F. diplosiphon. We also investigated whether c-di-AMP levels varied in these four cyanobacterial species under salt stress (Figure 7A). Under salt stress, c-di-AMP levels were not impacted in unicellular strains, whereas levels were lower in F. diplosiphon and higher in Anabaena in the presence of salt.

In cyanobacteria, biofilm formation is a protective mechanism against salt stress (Jittawuttipoka et al., 2013). We previously demonstrated that induction of biofilm formation is under the control of c-di-GMP in Synechocystis (Agostoni et al., 2016). To investigate whether c-di-GMP is elevated under salt stress conditions that are associated with cyanobacterial biofilm formation, we quantified c-di-GMP levels in response to treatment with salt. Indeed, c-di-GMP levels increased in all four species after $24 \mathrm{~h}$ of salt stress (Figure 7B). In contrast to stress caused by salt, the levels of c-di-GMP did not vary in Synechocystis, Synechococcus, and Anabaena under sorbitol stress (Figure 7B). However, c-di-GMP levels significantly increased under sorbitol stress in F. diplosiphon (Figure 7B). Taken together, these analyses suggest that $\mathrm{c}$-di-AMP responds to osmotic and salt stress, although generally an increase in c-diAMP levels is associated with sorbitol-induced osmotic stress (if there is a response). By contrast, levels of c-di-GMP primarily respond to ionic rather than osmotic stress across cyanobacterial species, with an increase in c-di-GMP levels observed in all tested strains in response to salt stress. The distinct responses of these cyanobacterial strains to salt and osmotic stresses may reflect 


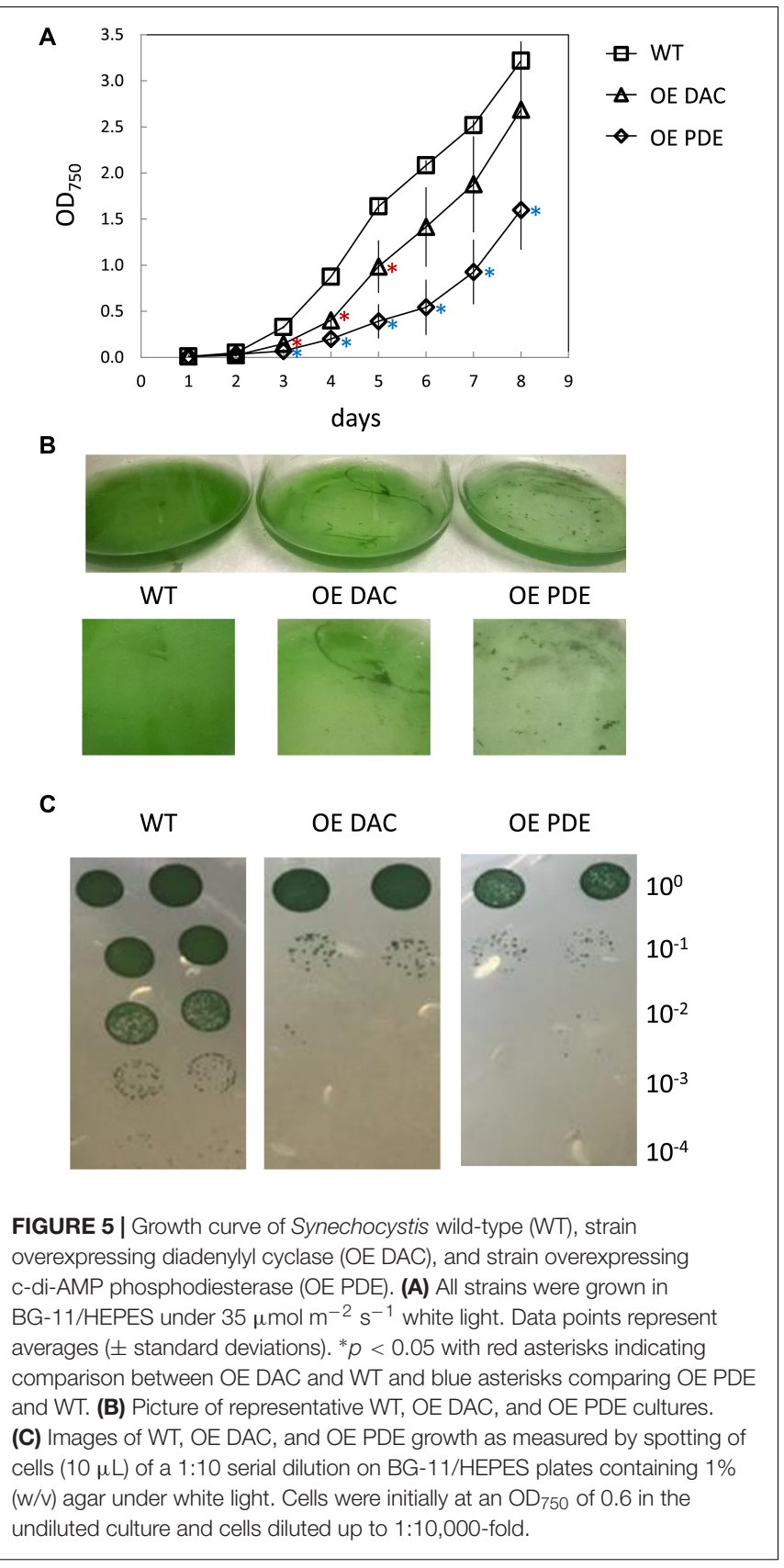

their distinct sensitivities to salt (Reed et al., 1985; Kaku et al., 2000; Rai and Tiwari, 2001; Singh and Montgomery, 2013b), as well as other aspects of their unique ecological histories. However, the production of c-di-AMP in a range of cyanobacterial species is evident.

Given that at least osmotic stress results in an alteration of intracellular c-di-AMP levels in Synechocystis, we queried whether strains with overexpression of DAC or PDE genes exhibited altered growth responses due to applied abiotic stresses. In these analyses, we reduced the intensity of white light to which cells were exposed (compared to results shown in Figure 5) due to the noted combined detrimental effect of multiple stresses such

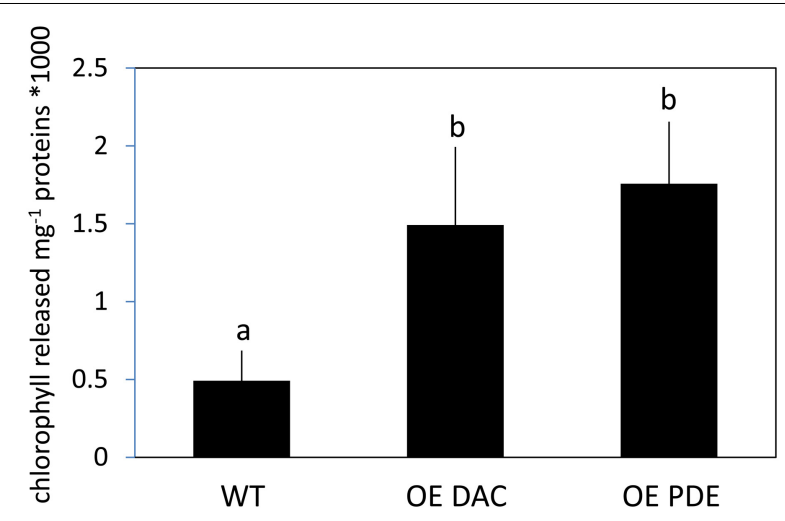

FIGURE 6 | Comparison of lysozyme-dependent lysis of Synechocystis wild-type (WT), strain overexpressing diadenylyl cyclase (OE DAC), and strain overexpressing c-di-AMP phosphodiesterase (OE PDE). All strains were grown in BG-11/HEPES under $15 \mu \mathrm{mol} \mathrm{m} \mathrm{m}^{-2} \mathrm{~s}^{-1}$ white light. Cells were treated with $10 \mu \mathrm{g} \mathrm{mL}^{-1}$ lysozyme for $30 \mathrm{~min}$. Cellular lysis was measured based on chlorophyll released from cells at measured by absorbance at $660 \mathrm{~nm}$ in the supernatant after centrifugation. Bars represent averages ( \pm standard deviations). Bars marked with different letters are significantly different $(p<0.05)$.

as high light and salt on cyanobacterial growth (Lu and Zhang, 2000). We first noted that, although not directly comparable due to changing multiple factors, growth under lower light (i.e., $\sim 15 \mu \mathrm{mol} \mathrm{m} \mathrm{m}^{-2} \mathrm{~s}^{-1}$ ) resulted in a significant impairment only of the OE PDE strain compared to WT compared to growth under higher white light (i.e., $35 \mu \mathrm{mol} \mathrm{m}^{-2} \mathrm{~s}^{-1}$ ). Additionally, OE DAC and OE PDE cells exposed to low light lacked a major lag in growth relative to WT that was observed at higher white light levels (compare Figure 5A and Figure 8A). Osmotic stress conditions had minor effects, with only the OE PDE strain having statistically significant, transiently improved growth relative to WT (Figure 8B). However, both OE PDE and OE DAC strains exhibited an impairment in growth relative to WT in the presence of salt (Figure 8C). The significant changes in growth under salt in the OE DAC and OE PDE strains relative to WT were associated with altered intracellular c-di-AMP levels. The OE DAC strain exhibited significantly higher intracellular c-di-AMP levels compared to WT, whereas c-di-AMP levels in the OE PDE strain were below detection when strains were grown in the presence of $\mathrm{NaCl}$ (Figure 9).

\section{DISCUSSION}

Given that the genus Gloeobacter, which is considered the most primordial of extant cyanobacteria (Rippka et al., 1974), possesses two DAC enzymes, in contrast with the majority of cyanobacterial species that have only have one DAC enzyme, we speculate that cyanobacteria initially contained two DAC enzymes and that during evolution the second DAC was lost. Since the conserved DAC, DAPDC and the UPS cassette (i.e., lysA-cdaA$u p p S$ operon) is extremely conserved among cyanobacteria, uniquely, and both the DAC and UPS have associations with peptidoglycan synthesis, these three genes together likely play a 

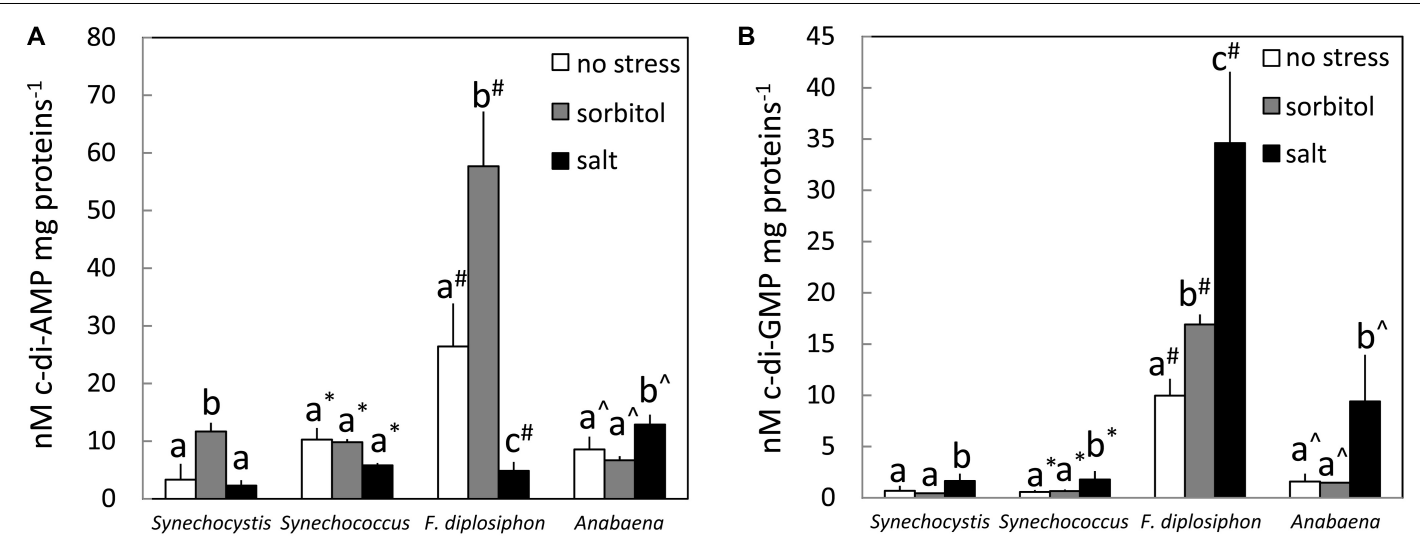

FIGURE 7 | Cyclic di-AMP and cyclic di-GMP levels under sorbitol and salt stresses. (A) Cyclic di-AMP and (B) cyclic di-GMP levels normalized to total proteins were determined for Synechocystis sp. PCC 6803 (Synechocystis), Synechococcus elongatus sp. PCC 7942 (Synechococcus), Fremyella diplosiphon (F. diplosiphon), and Anabaena sp. PCC 7120 (Anabaena) grown under $35 \mu \mathrm{mol} \mathrm{m}{ }^{-2} \mathrm{~s}^{-1}$ white light. Bars represent averages ( \pm standard deviations). Bars marked with different letters indicate a significant difference $(p<0.05)$ for comparisons made within each species.

critical role in controlling cell wall synthesis across cyanobacteria. This is a role consistent with prior studies which indicated that c-di-AMP metabolism impacts cell wall structure or stability in multiple, largely pathogenic, bacteria (Commichau et al., 2017). However, the conserved operon structure suggest an important and well-conserved function for c-di-AMP in peptidoglycandependent processes in cyanobacteria.

We were able to strongly increase transcript accumulation of DAC and PDE in Synechocystis using overexpression plasmids and demonstrate a significant impact on intracellular c-di-AMP levels in the OE DAC strain in BG-11 and significant impacts on c-di-AMP homeostasis in both the OE DAC and OE PDE strains grown in the presence of salt. Higher or lower levels of c-di-AMP are both detrimental to normal growth in Bacillus subtilis, Listeria monocytogenes, Borrelia burgdorferi, and Staphylococcus aureus (Corrigan et al., 2011; Dengler et al., 2013; Mehne et al., 2013; Witte et al., 2013; Ye et al., 2014). Also, reduced levels of c-diAMP have been recently shown to impact cyanobacterial growth in a Synechococcus strain in which $c d a A$ was deleted (Rubin et al., 2018). In B. subtilis the differences in growth rates between WT and a strain with strong accumulation of c-di-AMP were attributed to aberrant cell morphologies (Mehne et al., 2013). Given that the $c d a A$ gene is next to a gene encoding GImM that is essential for peptidoglycan synthesis in B. subtilis, the observed aberrant cell morphologies may be due to disruptions in c-di-AMP regulation of peptidogylan synthesis in the mutant compared to WT (Mehne et al., 2013). Mutation of the S. aureus PDE GdpP resulted in increased peptidoglycan cross-linking which was detrimental to growth (Corrigan et al., 2011).

Here, Synechocystis strains with overexpression of either DAC or PDE grew slower than WT. Notably, the DAC and PDE overexpression strains formed aggregates later in the growth analysis compared to WT which grew homogenously in the medium throughout. These phenotypes may be related to the observed changes in cell morphology or cell wall integrity of c-di-AMP mutants in several bacteria (Corrigan et al., 2011; Bai et al., 2013; Mehne et al., 2013; Witte et al., 2013;
Zhang and He, 2013; Tang et al., 2015). Indeed, the DAC and PDE overexpression strains exhibited increased sensitivity to lysozyme as compared to the WT parent strain. The results for the OE PDE strain are in accordance with prior analyses showing that decreased c-di-AMP levels have previously been implicated in cell wall sensitivity and altered cell lysis for a number of bacteria (Luo and Helmann, 2011; Witte et al., 2013). On the other hand, the increased sensitivity observed for the OE DAC strain may be associated with the fact that the $\mathrm{DAC} / \mathrm{cdaA}$ gene is in an operon with genes associated with cell wall synthesis/modification. Specifically, the role of the DADPC gene in crosslinking of peptidoglycan corresponds to prior associations of c-di-AMP levels with peptidoglycan crosslinking (Luo and Helmann, 2011). Thus, the altered phenotype of the OE DAC strain could be related to associated impacts of altering c-di-AMP accumulation on peptidoglycan crosslinking, which in turn could alter cellular responses to lysozyme.

Cyclic di-AMP homeostasis is critical in replete BG-11 medium. Additionally, the regulation of DAC and PDE genes in osmotic and salt stress, especially the latter, appears to contribute to cell fitness. Whereas WT has impaired growth in both stresses, changes in intracellular c-di-AMP homeostasis is important for cellular responses to salt stress as both the DAC and PDE OE strains, which have significantly higher and lower c-di-AMP levels in the presence of salt, respectively, exhibited impaired growth over time in the presence of $\mathrm{NaCl}$-induced stress.

Osmotic and ionic stresses are common in natural ecosystems (Williams, 1987; Kaushal et al., 2005; Durack et al., 2012; CanedoArguelles et al., 2013; El-Akhal et al., 2013) and identifying the mechanisms by which cyanobacteria can tolerate osmotic and ionic stresses is critical. Species able to maintain osmotic equilibrium under these conditions will prove most beneficial for use in cyanobacterial mass cultivation (Hagemann, 2011). There is still a lack of knowledge on the mechanisms used by cyanobacteria to specifically sense and respond to osmotic and ionic stresses. Experiments described here show that sorbitol is an important factor in the regulation of c-di-AMP homeostasis, 

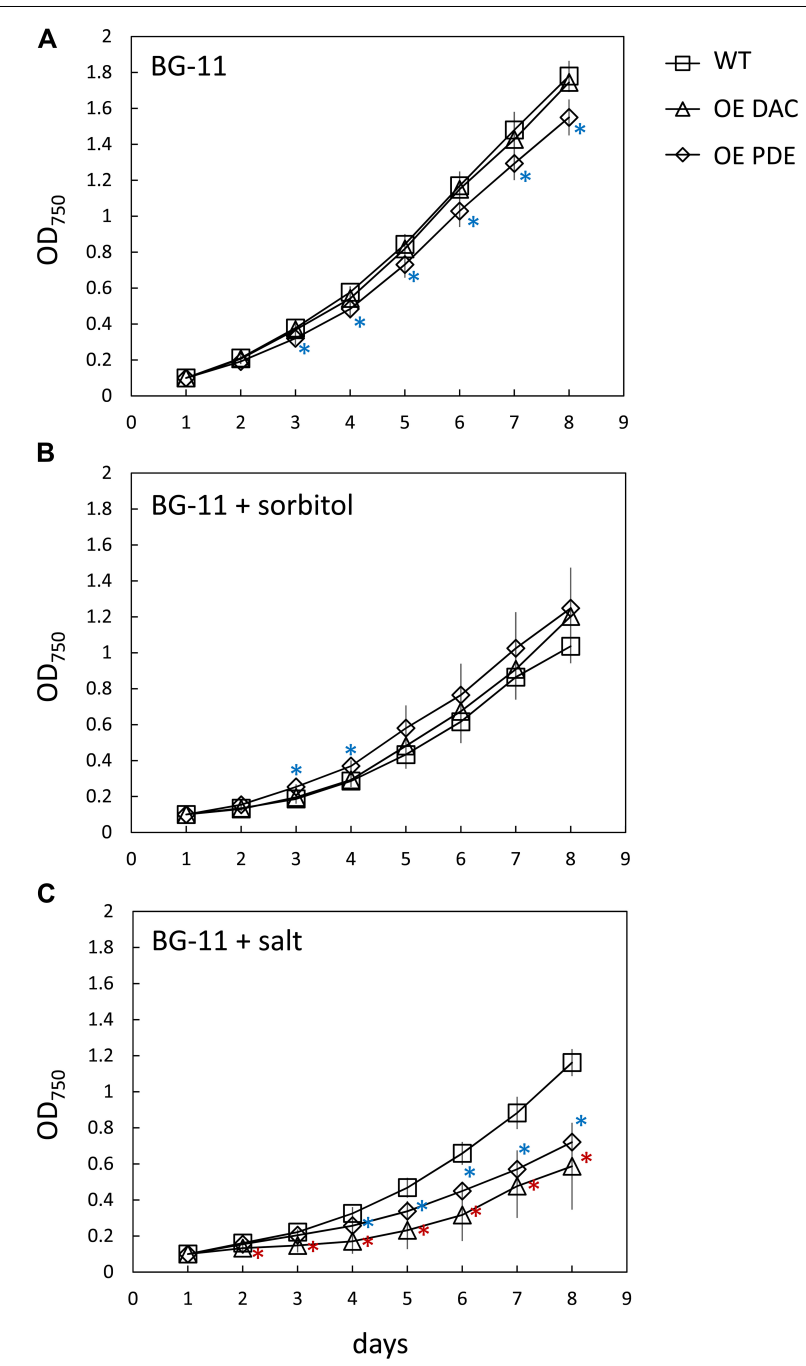

FIGURE 8 | Growth curve of Synechocystis wild-type (WT), strain overexpressing diadenylyl cyclase (OE DAC), and strain overexpressing c-di-AMP phosphodiesterase (OE PDE) under low white light and in presence of abiotic stresses. All strains were grown in BG-11/HEPES under $15 \mu \mathrm{mol} \mathrm{m} \mathrm{m}^{-2} \mathrm{~s}^{-1}$ white light in (A) BG-11 medium, (B) sorbitol-induced osmotic stress (0.5 M sorbitol), or (C) salt stress (0.6 M NaCl). Data points represent averages ( \pm standard deviations). ${ }^{*} p<0.05$ with red asterisks indicating comparison between OE DAC and WT and blue asterisks comparing OE PDE and WT.

whereas salt is a critical factor to regulate c-di-AMP synthesis and c-di-GMP homeostasis. Prior studies with Gram-positive bacteria have implicated c-di-AMP as critical during osmotic stress, based on the identification of a potassium transporter and a regulator of a $\mathrm{K}^{+}$transporter as c-di-AMP receptors (Corrigan et al., 2011, 2013; Bai et al., 2014; Moscoso et al., 2015). Also, regulation of c-di-AMP levels have been associated with salt sensitivity in Gram-positive strains (Smith et al., 2012; Dengler et al., 2013). Notably, a study on c-di-AMP-binding riboswitches implicated c-di-AMP-dependent regulation of the synthesis and transport of osmoprotectants in cyanobacteria as critical for stress responses, such as osmotic or salt stresses, in these organisms

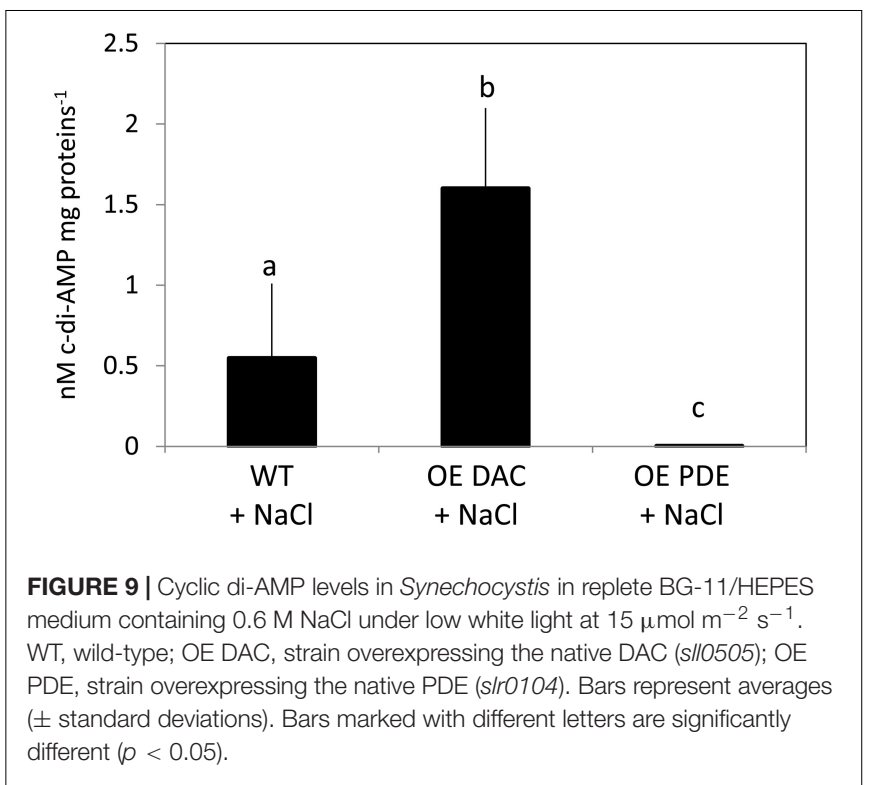

(Nelson et al., 2013). Our results suggest a role in response to salt stress in Synechocystis. Determining the molecular mechanisms of c-di-AMP and c-di-GMP signaling networks during cyanobacterial adaptation is necessary to understand how cyanobacteria survive in stressful and fluctuating environments and ensure improved biomass and product yields under osmotic and ionic stresses to improve applications and fundamental research in solving environmental problems.

\section{AUTHOR CONTRIBUTIONS}

MA and BM: conceived and designed the experiments. MA, AL-J, EH, GS, and EB: performed the experiments and contributed to data analysis. MA and BM: drafted the article. MA, AL-J, CW, and BM: critically revised the article.

\section{FUNDING}

This work was supported by the National Science Foundation (Grant No. MCB-1243983 to BM), the Michigan State University Discretionary Funding Initiative (Funding I.D. No. MSUDFI 70222 to BM), the National Institutes of Health (Grant Nos. GM109259 and AI130554 to CW) and support to Marco Agostoni from the United States Department of Energy (Chemical Sciences, Geosciences and Biosciences Division, Office of Basic Energy Sciences, Office of Science, Grant No. DE-FG0291ER20021 to BM). Participation of AL-J was additionally made possible by a predoctoral training award from Grant No. T32GM110523 from National Institute of General Medical Sciences of the National Institutes of Health and Alliance for Graduate Education and Professoriate (AGEP) Scholar Awards from the MSU Graduate School. The contents of this publication are solely the responsibility of the authors and do not necessarily represent the official views of the NIGMS or NIH. 


\section{REFERENCES}

Agostoni, M., Koestler, B. J., Waters, C. M., Williams, B. L., and Montgomery, B. L. (2013). Occurrence of cyclic di-GMP-modulating output domains in cyanobacteria: an illuminating perspective. mBio 4:e00451-13. doi: 10.1128/ mBio.00451-13

Agostoni, M., and Montgomery, B. L. (2014). Survival strategies in the aquatic and terrestrial world: the impact of second messengers on cyanobacterial processes. Life 4, 745-769. doi: 10.3390/life4040745

Agostoni, M., Waters, C. M., and Montgomery, B. L. (2016). Regulation of biofilm formation and cellular buoyancy through modulating intracellular cyclic diGMP levels in engineered cyanobacteria. Biotechnol. Bioeng. 113, 311-319. doi: 10.1002/bit.25712

Allen, M. M. (1968). Simple conditions for growth of unicellular blue-green algae on plates. J. Phycol. 4, 1-4. doi: 10.1111/j.1529-8817.1968.tb04667.x

Angerer, V., Schwenk, P., Wallner, T., Kaever, V., Hiltbrunner, A., and Wilde, A. (2017). The protein Slr1143 is an active diguanylate cyclase in Synechocystis sp. PCC 6803 and interacts with the photoreceptor Cph2. Microbiology 163, 920-930. doi: 10.1099/mic.0.000475

Apfel, C. M., Takacs, S., Fountoulakis, M., Stieger, M., and Keck, W. (1999). Use of genomics to identify bacterial undecaprenyl pyrophosphate synthetase: cloning, expression, and characterization of the essential uppS gene. J. Bacteriol. 181, 483-492.

Bai, Y., Yang, J., Eisele, L. E., Underwood, A. J., Koestler, B. J., Waters, C. M., et al. (2013). Two DHH subfamily 1 proteins in Streptococcus pneumoniae possess cyclic Di-AMP phosphodiesterase activity and affect bacterial growth and virulence. J. Bacteriol. 195, 5123-5132. doi: 10.1128/jb.00769-13

Bai, Y., Yang, J., Zarrella, T. M., Zhang, Y., Metzger, D. W., and Bai, G. (2014). Cyclic di-AMP impairs potassium uptake mediated by a cyclic di-AMP binding protein in Streptococcus pneumoniae. J. Bacteriol. 196, 614-623. doi: 10.1128/jb. 01041-13

Barker, J. R., Koestler, B. J., Carpenter, V. K., Burdette, D. L., Waters, C. M., Vance, R. E., et al. (2013). STING-dependent recognition of cyclic di-AMP mediates type I interferon responses during Chlamydia trachomatis infection. mBio 4:e00018-13. doi: 10.1128/mBio.00018-13

Bejerano-Sagie, M., Oppenheimer-Shaanan, Y., Berlatzky, I., Rouvinski, A., Meyerovich, M., and Ben-Yehuda, S. (2006). A checkpoint protein that scans the chromosome for damage at the start of sporulation in Bacillus subtilis. Cell 125, 679-690. doi: 10.1016/j.cell.2006.03.039

Bougouffa, S., Radovanovic, A., Essack, M., and Bajic, V. B. (2014). DEOP: a database on osmoprotectants and associated pathways. Database 2014:bau100. doi: 10.1093/database/bau100

Bowman, L., Zeden, M. S., Schuster, C. F., Kaever, V., and Gründling, A. (2016). New insights into the cyclic Di-adenosine monophosphate (c-di-AMP) degradation pathway and the requirement of the cyclic dinucleotide for acid stress resistance in Staphylococcus aureus. J. Biol. Chem. 291, 26970-26986. doi: 10.1074/jbc.M116.747709

Bukhari, A. I., and Taylor, A. L. (1971a). Genetic analysis of diaminopimelic acidand lysine-requiring mutants of Escherichia coli. J. Bacteriol. 105, 844-854.

Bukhari, A. I., and Taylor, A. L. (1971b). Mutants of Escherichia coli with a growth requirement for either lysine or pyridoxine. J. Bacteriol. 105, 988-998.

Cadoret, J.-C., Rousseau, B., Perewoska, I., Sicora, C., Cheregi, O., Vass, I., et al. (2005). Cyclic nucleotides, the photosynthetic apparatus and response to a UVB stress in the cyanobacterium Synechocystis sp. PCC 6803. J. Biol. Chem. 280, 33935-33944.

Canedo-Arguelles, M., Kefford, B. J., Piscart, C., Prat, N., Schafer, R. B., and Schulz, C. J. (2013). Salinisation of rivers: an urgent ecological issue. Environ. Pollut. 173, 157-167. doi: 10.1016/j.envpol.2012.10.011

Cho, K. H., and Kang, S. O. (2013). Streptococcus pyogenes c-di-AMP phosphodiesterase. GdpP, influences SpeB processing and virulence. PLoS One 8:e69425. doi: 10.1371/journal.pone.0069425

Cobley, J. G., Zerweck, E., Reyes, R., Mody, A., Seludounson, J. R., Jaeger, H., et al. (1993). Construction of shuttle plasmids which can be efficiently mobilized from Escherichia coli into the chromatically adapting cyanobacterium, Fremyella diplosiphon. Plasmid 30, 90-105. doi: 10.1006/plas.1993.1037

Commichau, F. M., Dickmanns, A., Gundlach, J., Ficner, R., and Stülke, J. (2015). A jack of all trades: the multiple roles of the unique essential second messenger cyclic di-AMP. Mol. Microbiol. 97, 189-204. doi: 10.1111/mmi.13026
Commichau, F. M., Gibhardt, J., Halbedel, S., Gundlach, J., and Stülke, J. (2017). A delicate connection: c-di-AMP affects cell integrity by controlling osmolyte transport. Trends Microbiol. 26, 175-185. doi: 10.1016/j.tim.2017.1009.1003

Corrigan, R. M., Abbott, J. C., Burhenne, H., Kaever, V., and Grundling, A. (2011). c-di-AMP Is a new second messenger in Staphylococcus aureus with a role in controlling cell size and envelope stress. PLoS Pathog. 7:e1002217. doi: 10.1371/ journal.ppat.1002217

Corrigan, R. M., Campeotto, I., Jeganathan, T., Roelofs, K. G., Lee, V. T., and Gründling, A. (2013). Systematic identification of conserved bacterial c-diAMP receptor proteins. Proc. Natl. Acad. Sci. U.S.A. 110, 9084-9089. doi: 10. $1073 /$ pnas. 1300595110

Corrigan, R. M., and Grundling, A. (2013). Cyclic di-AMP: another second messenger enters the fray. Nat. Rev. Microbiol. 11, 513-524. doi: 10.1038/ nrmicro3069

Dengler, V., Mccallum, N., Kiefer, P., Christen, P., Patrignani, A., Vorholt, J. A., et al. (2013). Mutation in the c-di-AMP cyclase dacA affects fitness and resistance of methicillin resistant Staphylococcus aureus. PLoS One 8:e73512. doi: 10.1371/journal.pone.0073512

Dey, B., Dey, R. J., Cheung, L. S., Pokkali, S., Guo, H., Lee, J.-H., et al. (2015). A bacterial cyclic dinucleotide activates the cytosolic surveillance pathway and mediates innate resistance to tuberculosis. Nat. Med. 21, 401-406. doi: 10.1038/ nm.3813

Du, B., Ji, W., An, H., Shi, Y., Huang, Q., Cheng, Y., et al. (2014). Functional analysis of c-di-AMP phosphodiesterase, GdpP, in Streptococcus suis serotype 2. Microbiol. Res. 169, 749-758. doi: 10.1016/j.micres.2014.01.002

Durack, P. J., Wijffels, S. E., and Matear, R. J. (2012). Ocean salinities reveal strong global water cycle intensification during 1950 to 2000. Science 336, 455-458. doi: 10.1126/science.1212222

Edgar, R. C. (2004). MUSCLE: multiple sequence alignment with high accuracy and high throughput. Nucleic Acids Res. 32, 1792-1797. doi: 10.1093/nar/gkh340

El-Akhal, M. R., Rincon, A., Coba De La Pena, T., Lucas, M. M., El Mourabit, N., Barrijal, S., et al. (2013). Effects of salt stress and rhizobial inoculation on growth and nitrogen fixation of three peanut cultivars. Plant Biol. 15, 415-421. doi: 10.1111/j.1438-8677.2012.00634.x

Enomoto, G., Ni-Ni-Win, Narikawa, R., and Ikeuchi, M. (2015). Three cyanobacteriochromes work together to form a light color-sensitive input system for c-di-GMP signaling of cell aggregation. Proc. Natl. Acad. Sci. U.S.A. 112, 8082-8087. doi: 10.1073/pnas.1504228112

Enomoto, G., Nomura, R., Shimada, T., Ni-Ni Win, Narikawa, R., and Ikeuchi, M. (2014). Cyanobacteriochrome SesA is a diguanylate cyclase that induces cell aggregation in Thermosynechococcus. J. Biol. Chem. 289, 24801-24809. doi: 10.1074/jbc.M114.583674

Fu, T., Zhao, Y., and Xi, J. (2016). A new second messenger: bacterial c-di-AMP. Crit. Rev. Eukaryot. Gene Expr. 26, 309-316. doi: 10.1615/ CritRevEukaryotGeneExpr.2016016642

Galtier, N., Gouy, M., and Gautier, C. (1996). SeaView and Phylo_win: two graphic tools for sequence alignment and molecular phylogeny. Comput. Appl. Biosci. 12, 543-548. doi: 10.1093/bioinformatics/12.6.543

Gándara, C., and Alonso, J. C. (2015). DisA and c-di-AMP act at the intersection between DNA-damage response and stress homeostasis in exponentially growing Bacillus subtilis cells. DNA Repair 27, 1-8. doi: 10.1016/j.dnarep.2014. 12.007

Gándara, C., De Lucena, D. K. C., Torres, R., Serrano, E., Altenburger, S., Graumann, P. L., et al. (2017). Activity and in vivo dynamics of Bacillus subtilis DisA are affected by RadA/Sms and by Holliday junction-processing proteins. DNA Repair 55, 17-30. doi: 10.1016/j.dnarep.2017.05.002

Garcia-Pichel, F., Belnap, J., Neuer, S., and Schanz, F. (2003). Estimates of global cyanobacterial biomass and its distribution. Algol. Stud. 109, 213-227. doi: 10.1127/1864-1318/2003/0109-0213

Gundlach, J., Mehne, F. M., Herzberg, C., Kampf, J., Valerius, O., Kaever, V., et al. (2015). An essential poison: synthesis and degradation of cyclic di-AMP in Bacillus subtilis. J. Bacteriol. 197, 3265-3274. doi: 10.1128/jb.00564-15

Hagemann, M. (2011). Molecular biology of cyanobacterial salt acclimation. FEMS Microbiol. Rev. 35, 87-123. doi: 10.1111/j.1574-6976.2010.00234.x

Huynh, T. N., Luo, S., Pensinger, D., Sauer, J. D., Tong, L., and Woodward, J. J. (2015). An HD-domain phosphodiesterase mediates cooperative hydrolysis of c-di-AMP to affect bacterial growth and virulence. Proc. Natl. Acad. Sci. U.S.A. 112, E747-E756. doi: 10.1073/pnas.1416485112 
Huynh, T. N., and Woodward, J. J. (2016). Too much of a good thing: regulated depletion of c-di-AMP in the bacterial cytoplasm. Curr. Opin. Microbiol. 30, 22-29. doi: 10.1016/j.mib.2015.12.007

Imashimizu, M., Yoshimura, H., Katoh, H., Ehira, S., and Ohmori, M. (2005). $\mathrm{NaCl}$ enhances cellular cAMP and upregulates genes related to heterocyst development in the cyanobacterium, Anabaena sp. strain PCC 7120. FEMS Microbiol. Lett. 252, 97-103. doi: 10.1016/j.femsle.2005.08.035

Jenal, U., Reinders, A., and Lori, C. (2017). Cyclic di-GMP: second messenger extraordinaire. Nat. Rev. Microbiol. 15, 271-284. doi: 10.1038/nrmicro.2016.190

Jittawuttipoka, T., Planchon, M., Spalla, O., Benzerara, K., Guyot, F., CassierChauvat, C., et al. (2013). Multidisciplinary evidences that Synechocystis PCC6803 exopolysaccharides operate in cell sedimentation and protection against salt and metal stresses. PLoS One 8:e55564. doi: 10.1371/journal.pone. 0055564

Jones, D. T., Taylor, W. R., and Thornton, J. M. (1992). The rapid generation of mutation data matrices from protein sequences. Comput. Appl. Biosci. 8, 275-282. doi: 10.1093/bioinformatics/8.3.275

Kaku, N., Hibino, T., Tanaka, Y., Ishikawa, H., Araki, E., Takabe, T., et al. (2000). Effects of overexpression of Escherichia coli katE and bet genes on the tolerance for salt stress in a freshwater cyanobacterium Synechococcus sp. PCC 7942. Plant Sci. 159, 281-288.

Katayama, M., and Ohmori, M. (1997). Isolation and characterization of multiple adenylate cyclase genes from the cyanobacterium Anabaena sp. strain PCC 7120. J. Bacteriol. 179, 3588-3593. doi: 10.1128/jb.179.11.3588-3593.1997

Kaushal, S. S., Groffman, P. M., Likens, G. E., Belt, K. T., Stack, W. P., Kelly, V. R., et al. (2005). Increased salinization of fresh water in the northeastern United States. Proc. Natl. Acad. Sci. U.S.A. 102, 13517-13520. doi: 10.1073/pnas. 0506414102

Kloft, N., Rasch, G., and Forchhammer, K. (2005). Protein phosphatase PphA from Synechocystis sp. PCC 6803: the physiological framework of PII-P dephosphorylation. Microbiology 151, 1275-1283. doi: 10.1099/mic.0. 27771-0

Krasteva, P. V., and Sondermann, H. (2017). Versatile modes of cellular regulation via cyclic dinucleotides. Nat. Chem. Biol. 13, 350-359. doi: 10.1038/nchembio. 2337

Lu, C., and Zhang, J. (2000). Role of light in the response of PSII photochemistry to salt stress in the cyanobacterium Spirulina platensis. J. Exp. Bot. 51, 911-917. doi: $10.1093 / \mathrm{jxb} / 51.346 .911$

Luo, Y., and Helmann, J. D. (2011). Analysis of the role of Bacillus subtilis $\sigma \mathrm{M}$ in $\beta$-lactam resistance reveals an essential role for c-di-AMP in peptidoglycan homeostasis. Mol. Microbiol. 83, 623-639. doi: 10.1111/j.1365-2958.2011. 07953.x

Marin, K., Suzuki, I., Yamaguchi, K., Ribbeck, K., Yamamoto, H., Kanesaki, Y., et al. (2003). Identification of histidine kinases that act as sensors in the perception of salt stress in Synechocystis sp. PCC 6803. Proc. Natl. Acad. Sci. U.S.A. 100, 9061-9066. doi: 10.1073/pnas.1532302100

Massie, J. P., Reynolds, E. L., Koestler, B. J., Cong, J. P., Agostoni, M., and Waters, C. M. (2012). Quantification of high-specificity cyclic diguanylate signaling. Proc. Natl. Acad. Sci. U.S.A. 109, 12746-12751. doi: 10.1073/pnas.11156 63109

Mehne, F. M., Schröder-Tittmann, K., Eijlander, R. T., Herzberg, C., Hewitt, L., Kaever, V., et al. (2014). Control of the diadenylate cyclase CdaS in Bacillus subtilis: an autoinhibitory domain limits cyclic di-AMP production. J. Biol. Chem. 289, 21098-21107. doi: 10.1074/jbc.M114.562066

Mehne, F. M. P., Gunka, K., Eilers, H., Herzberg, C., Kaever, V., and Stulke, J. (2013). Cyclic di-AMP homeostasis in Bacillus subtilis: both lack and high level accumulation of the nucleotide are detrimental for cell growth. J. Biol. Chem. 288, 2004-2017. doi: 10.1074/jbc.M112.395491

Mehta, K. K., Evitt, N. H., and Swartz, J. R. (2015). Chemical lysis of cyanobacteria. J. Biol. Eng. 9:10. doi: 10.1186/s13036-015-0007-y

Mikami, K., Kanesaki, Y., Suzuki, I., and Murata, N. (2002). The histidine kinase Hik33 perceives osmotic stress and cold stress in Synechocystis sp. PCC 6803. Mol. Microbiol. 46, 905-915.

Moscoso, J. A., Schramke, H., Zhang, Y., Tosi, T., Dehbi, A., Jung, K., et al. (2015). Binding of cyclic di-AMP to the Staphylococcus aureus sensor kinase $\mathrm{KdpD}$ occurs via the universal stress protein domain and downregulates the expression of the Kdp potassium transporter. J. Bacteriol. 198, 98-110. doi: $10.1128 /$ jb.00480- 15
Nelson, J. W., Sudarsan, N., Furukawa, K., Weinberg, Z., Wang, J. X., and Breaker, R. R. (2013). Riboswitches in eubacteria sense the second messenger c-di-AMP. Nat. Chem. Biol. 9, 834-839. doi: 10.1038/nchembio.1363

Ochoa De Alda, J. A. G., Ajlani, G., and Houmard, J. (2000). Synechocystis strain PCC 6803 cya2, a prokaryotic gene that encodes a guanylyl cyclase. J. Bacteriol. 182, 3839-3842. doi: 10.1128/jb.182.13.3839-3842.2000

Ohmori, M., Ikeuchi, M., Sato, N., Wolk, P., Kaneko, T., Ogawa, T., et al. (2001). Characterization of genes encoding multi-domain proteins in the genome of the filamentous nitrogen-fixing cyanobacterium Anabaena sp. strain PCC 7120. DNA Res. 8, 271-284.

Ohmori, M., Ohmori, K., and Hasunuma, K. (1988). Rapid change in cyclic $3^{\prime}, 5^{\prime}$-AMP concentration triggered by a light-off or light-on signal in Anabaena cylindrica. Arch. Microbiol. 150, 203-204. doi: 10.1007/BF00 425163

Ohmori, M., and Okamoto, S. (2004). Photoresponsive cAMP signal transduction in cyanobacteria. Photochem. Photobiol. Sci. 3, 503-511. doi: 10.1039/b401623h

Ohmori, M., Terauchi, K., Okamoto, S., and Watanabe, M. (2002). Regulation of cAMP-mediated photosignaling by a phytochrome in the cyanobacterium Anabaena cylindrica. Photochem. Photobiol. 75, 675-679. doi: 10.1562/00318655(2002)075<0675:ROCMPB > 2.0.CO;2

Okamoto, S., Kasahara, M., Kamiya, A., Nakahira, Y., and Ohmori, M. (2004). A phytochrome-like protein AphC triggers the cAMP signaling induced by far-red light in the cyanobacterium Anabaena sp. strain PCC7120. Photochem. Photobiol. 80, 429-433. doi: 10.1562/0031-8655(2004)080<0429:APPATT $>2.0$. $\mathrm{CO} ; 2$

Oppenheimer-Shaanan, Y., Wexselblatt, E., Katzhendler, J., Yavin, E., and BenYehuda, S. (2011). c-di-AMP reports DNA integrity during sporulation in Bacillus subtilis. EMBO Rep. 12, 594-601. doi: 10.1038/embor.2011.77

Pade, N., and Hagemann, M. (2015). Salt acclimation of cyanobacteria and their application in biotechnology. Life 5, 25-49. doi: 10.3390/life5010025

Paithoonrangsarid, K., Shoumskaya, M. A., Kanesaki, Y., Satoh, S., Tabata, S., Los, D. A., et al. (2004). Five histidine kinases perceive osmotic stress and regulate distinct sets of genes in Synechocystis. J. Biol. Chem. 279, 53078-53086. doi: $10.1074 /$ jbc.M410162200

Pattanaik, B., and Montgomery, B. L. (2010). FdTonB is involved in the photoregulation of cellular morphology during complementary chromatic adaptation in Fremyella diplosiphon. Microbiology 156, 731-741. doi: 10.1099/ mic.0.035410-0

Raguse, M., Torres, R., Seco, E. M., Gándara, C., Ayora, S., Moeller, R., et al. (2017). Bacillus subtilis DisA helps to circumvent replicative stress during spore revival. DNA Repair 59, 57-68. doi: 10.1016/j.dnarep.2017.09.006

Rai, A. K., and Tiwari, S. P. (2001). $\mathrm{NO}_{3}$ - nutrition and salt tolerance in the cyanobacterium Anabaena sp. PCC 7120 and mutant strains. J. Appl. Microbiol. 86, 991-998. doi: 10.1046/j.1365-2672.1999.00788.x

Reed, R. H., Richardson, D. L., and Stewart, W. D. P. (1985). $\mathrm{Na}^{+}$uptake and extrusion in the cyanobacterium Synechocystis PCC 6714 in response to hypersaline treatment. Evidence for transient changes in plasmalemma $\mathrm{Na}^{+}$ permeability. Biochim. Biophys. Acta 814, 347-355. doi: 10.1016/0005-2736(85) 90455-9

Rippka, R., Waterbury, J., and Cohen-Bazire, G. (1974). A cyanobacterium which lacks thylakoids. Arch. Microbiol. 100, 419-436. doi: 10.1007/bf00446333

Rismondo, J., Gibhardt, J., Rosenberg, J., Kaever, V., Halbedel, S., and Commichau, F. M. (2016). Phenotypes associated with the essential diadenylate cyclase CdaA and its potential regulator $\mathrm{CdaR}$ in the human pathogen Listeria monocytogenes. J. Bacteriol. 198, 416-426. doi: 10.1128/jb.00845-15

Romling, U. (2008). Great times for small molecules: c-di-AMP, a second messenger candidate in Bacteria and Archaea. Sci. Signal. 1:pe39. doi: 10.1126/ scisignal.133pe39

Rubin, B. E., Huynh, T. N., Welkie, D. G., Diamond, S., Simkovsky, R., Pierce, E. C., et al. (2018). High-throughput interaction screens illuminate the role of c-di-AMP in cyanobacterial nighttime survival. PLoS Genet. 14:e1007301. doi: 10.1371/journal.pgen.1007301

Savage, C. R., Arnold, W. K., Gjevre-Nail, A., Koestler, B. J., Bruger, E. L., Barker, J. R., et al. (2015). Intracellular concentrations of Borrelia burgdorferi cyclic diAMP are not changed by altered expression of the cdaA synthase. PLoS One 10:e0125440. doi: 10.1371/journal.pone.0125440

Savakis, P., De Causmaecker, S., Angerer, V., Ruppert, U., Anders, K., Essen, L. O., et al. (2012). Light-induced alteration of c-di-GMP level controls motility of 
Synechocystis sp, PCC 6803. Mol. Microbiol. 85, 239-251. doi: 10.1111/j.13652958.2012.08106.x

Seib, L. O., and Kehoe, D. M. (2002). A turquoise mutant genetically separates expression of genes encoding phycoerythrin and its associated linker peptides. J. Bacteriol. 184, 962-970. doi: 10.1128/jb.184.4.962-970.2002

Shih, P. M., Wu, D. Y., Latifi, A., Axen, S. D., Fewer, D. P., Talla, E., et al. (2013). Improving the coverage of the cyanobacterial phylum using diversity-driven genome sequencing. Proc. Natl. Acad. Sci. U.S.A. 110, 1053-1058. doi: 10.1073/ pnas. 1217107110

Shoumskaya, M. A., Paithoonrangsarid, K., Kanesaki, Y., Los, D. A., Zinchenko, V. V., Tanticharoen, M., et al. (2005). Identical Hik-Rre systems are involved in perception and transduction of salt signals and hyperosmotic signals but regulate the expression of individual genes to different extents in Synechocystis. J. Biol. Chem. 280, 21531-21538. doi: 10.1074/jbc.M412174200

Singh, S. P., and Montgomery, B. L. (2013a). Distinct salt-dependent effects impair Fremyella diplosiphon pigmentation and cellular shape. Plant Signal. Behav. 8:e24713. doi: 10.4161/psb.24713

Singh, S. P., and Montgomery, B. L. (2013b). Salinity impacts photosynthetic pigmentation and cellular morphology changes by distinct mechanisms in Fremyella diplosiphon. Biochem. Biophys. Res. Commun. 33, 84-89. doi: 10.1016/ j.bbrc.2013.02.060

Smith, W. M., Pham, T. H., Lei, L., Dou, J., Soomro, A. H., Beatson, S. A., et al. (2012). Heat resistance and salt hypersensitivity in Lactococcus lactis due to spontaneous mutation of llmg_1816 (gdpP) induced by high-temperature growth. Appl. Environ. Microbiol. 78, 7753-7759. doi: 10.1128/aem.02316-12

Tang, Q., Luo, Y., Zheng, C., Yin, K., Ali, M. K., Li, X., et al. (2015). Functional analysis of a c-di-AMP-specific phosphodiesterase MsPDE from Mycobacterium smegmatis. Int. J. Biol. Sci. 11, 813-824. doi: 10.7150/ijbs.11797

Terauchi, K., and Ohmori, M. (1999). An adenylate cyclase, cyal, regulates cell motility in the cyanobacterium Synechocystis sp. PCC 6803. Plant Cell Physiol. 40, 248-251.

Terauchi, K., and Ohmori, M. (2004). Blue light stimulates cyanobacterial motility via a cAMP signal transduction system. Mol. Microbiol. 52, 303-309. doi: 10. 1111/j.1365-2958.2003.03980.x

Torrecilla, I., Leganés, F., Bonilla, I., and Fernández-Piñas, F. (2001). Calcium transients in response to salinity and osmotic stress in the nitrogen-fixing cyanobacterium Anabaena sp. PCC7120, expressing cytosolic apoaequorin. Plant Cell Environ. 24, 641-648. doi: 10.1046/j.0016-8025.2001.00708.x

Townsley, L., Yannarell, S. M., Huynh, T. N., Woodward, J. J., and Shank, E. A. (2018). Cyclic di-AMP acts as an extracellular signal that impacts Bacillus subtilis biofilm formation and plant attachment. mBio 9:e00341-18. doi: 10 . 1128/mBio.00341- 18

Turner, S., Pryer, K. M., Miao, V. P. W., and Palmer, J. D. (1999). Investigating deep phylogenetic relationships among cyanobacteria and plastids by small submit rRNA sequence analysis. J. Eukaryot. Microbiol. 46, 327-338. doi: 10.1111/j. 1550-7408.1999.tb04612.x

Wang, J., Zhang, X., Shi, M., Gao, L., Niu, X., Te, R., et al. (2014). Metabolomic analysis of the salt-sensitive mutants reveals changes in amino acid and fatty acid composition important to long-term salt stress in Synechocystis sp. PCC 6803. Funct. Integr. Genomics 14, 431-440. doi: 10.1007/s10142-0140370-7

Whiteley, A. T., Garelis, N. E., Peterson, B. N., Choi, P. H., Tong, L., Woodward, J. J., et al. (2017). c-di-AMP modulates Listeria monocytogenes central metabolism to regulate growth, antibiotic resistance and osmoregulation. Mol. Microbiol. 104, 212-233. doi: 10.1111/mmi.13622
Williams, W. D. (1987). Salinization of rivers and streams: an important environmental hazard. Ambio 16, 180-185.

Witte, C. E., Whiteley, A. T., Burke, T. P., Sauer, J. D., Portnoy, D. A., and Woodward, J. J. (2013). Cyclic di-AMP is critical for Listeria monocytogenes growth, cell wall homeostasis, and establishment of infection. mBio 4:e0028213. doi: $10.1128 / \mathrm{mBio} .00282-13$

Witte, G., Hartung, S., Büttner, K., and Hopfner, K.-P. (2008). Structural biochemistry of a bacterial checkpoint protein reveals diadenylate cyclase activity regulated by DNA recombination intermediates. Mol. Cell 30, 167-178. doi: 10.1016/j.molcel.2008.02.020

Wolk, C. P., Fan, Q., Zhou, R., Huang, G., Lechno-Yossef, S., Kuritz, T., et al. (2007). Paired cloning vectors for complementation of mutations in the cyanobacterium Anabaena sp. strain PCC 7120. Arch. Microbiol. 188, 551-563. doi: 10.1007/s00203-007-0276-Z

Yang, J., Bai, Y., Zhang, Y., Gabrielle, V. D., Jin, L., and Bai, G. (2014). Deletion of the cyclic di-AMP phosphodiesterase gene ( $\mathrm{cnpB}$ ) in Mycobacterium tuberculosis leads to reduced virulence in a mouse model of infection. Mol. Microbiol. 93, 65-79. doi: 10.1111/mmi.12641

Ye, M., Zhang, J. J., Fang, X., Lawlis, G. B., Troxell, B., Zhou, Y., et al. (2014). DhhP, a cyclic di-AMP phosphodiesterase of Borrelia burgdorferi, is essential for cell growth and virulence. Infect. Immun. 82, 1840-1849. doi: 10.1128/iai.00030-14

Yerrapragada, S., Shukla, A., Hallsworth-Pepin, K., Choi, K., Wollam, A., Clifton, S., et al. (2015). Extreme sensory complexity encoded in the 10-Megabase draft genome sequence of the chromatically acclimating cyanobacterium Tolypothrix sp. PCC 7601. Genome Announc. 3:e00355-15. doi: 10.1128/genomeA.00355-15

Zhang, L., and He, Z. G. (2013). Radiation-sensitive gene A (RadA) targets DisA, DNA integrity scanning protein A, to negatively affect cyclic Di-AMP synthesis activity in Mycobacterium smegmatis. J. Biol. Chem. 288, 22426-22436. doi: 10.1074/jbc.M113.464883

Zhang, P., Sicora, C. I., Vorontsova, N., Allahverdiyeva, Y., Battchikova, N., Nixon, P. J., et al. (2007). FtsH protease is required for induction of inorganic carbon acquisition complexes in Synechocystis sp. PCC 6803. Mol. Microbiol. 65, 728-740. doi: 10.1111/j.1365-2958.2007.05822.x

Zheng, C., Ma, Y., Wang, X., Xie, Y., Ali, M. K., and He, J. (2015). Functional analysis of the sporulation-specific diadenylate cyclase CdaS in Bacillus thuringiensis. Front. Microbiol. 6:908. doi: 10.3389/fmicb.2015.00908

Zhu, Y., Pham, T. H., Nhiep, T. H. N., Vu, N. M. T., Marcellin, E., Chakrabortti, A., et al. (2016). Cyclic-di-AMP synthesis by the diadenylate cyclase CdaA is modulated by the peptidoglycan biosynthesis enzyme GlmM in Lactococcus lactis. Mol. Microbiol. 99, 1015-1027. doi: 10.1111/mmi.13281

Conflict of Interest Statement: The authors declare that the research was conducted in the absence of any commercial or financial relationships that could be construed as a potential conflict of interest.

The reviewer RS and handling Editor declared their shared affiliation.

Copyright (c) 2018 Agostoni, Logan-Jackson, Heinz, Severin, Bruger, Waters and Montgomery. This is an open-access article distributed under the terms of the Creative Commons Attribution License (CC BY). The use, distribution or reproduction in other forums is permitted, provided the original author(s) and the copyright owner are credited and that the original publication in this journal is cited, in accordance with accepted academic practice. No use, distribution or reproduction is permitted which does not comply with these terms. 